\title{
PROPOSTA DE PRÉ-QUALIFICAÇÃO POZOLÂNICA DE MATERIAIS GEOLÓGICOS: DIFRATOMETRIA DE RAIOS X COMO MÉTODO ALTERNATIVO
}

\author{
Tarcísio José MONTANHEIRO \\ Jorge Kazuo YAMAMOTO \\ Yushiro KIHARA
}

\begin{abstract}
RESUMO
Este trabalho apresenta um método alternativo para estimar o potencial pozolânico de materiais geológicos, baseado na análise de difração de raios $\mathrm{X}$ de argamassas obtidas a partir de uma mistura de duas partes de cal (hidróxido de cálcio) e uma parte de material moído e água. A mistura é colocada para secar em estufa a $30^{\circ} \mathrm{C}$ durante 7 dias, quando é avaliada a capacidade de reação e fixação de cal pela determinação da resistência à compressão. A argamassa é moída e submetida à difração de raios $\mathrm{X}$, que revela os compósitos neoformados como produtos da reação pozolânica. Os componentes mais importantes estão associados ao silicato de cálcio hidratado (C-S-H) e suas formas derivadas com alumínio, ferro, sódio e potássio. A presença desses novos compostos indica que o material geológico pode apresentar uma reação pozolânica favorável e, portanto, constituir uma pozolana natural.
\end{abstract}

Palavras-chave: método de pozolanicidade, pozolanas, difração de raios X

\begin{abstract}
This paper presents an alternative method for the evaluation of the pozzolanic potential of geological materials. This method is based on $\mathrm{X}$ ray powder diffraction analysis of mortars obtained from a mixture of two parts of lime (calcium hydroxide) and one part of ground material and water. The mixture is put to dry in an oven at $30^{\circ} \mathrm{C}$ during 7 days when maximum consumption of lime due to pozzolanic reaction occurs. The mortar is ground and then submitted to $\mathrm{X}$ ray powder diffraction analysis, which reveals new compounds formed as products of pozzolanic reaction. The most important compounds are associated with hydrated calcium silicate (C-S-H) and its derivatives with aluminum, iron, sodium and potassium. The presence of these new compounds indicates that the geological material may present a favorable pozzolanic reaction and be, therefore, a natural pozzolan.
\end{abstract}

Keywords: pozzolanic method, pozzolan, $\mathrm{X}$ ray powder diffraction analysis

\section{INTRODUÇÃO}

O cimento pozolânico é definido como um aglomerante hidráulico, resultante da moagem do clínquer Portland e pozolana, sem nenhuma outra substância adicionada senão uma ou mais formas de sulfato de cálcio. A adição adequada de pozolanas ao clínquer Portland comum apresenta alguns benefícios já referidos por MIELENZ et al. (1951): custa menos, reduz o calor de hidratação, tem moabilidade melhora- da, diminui a permeabilidade e melhora a plasticidade do concreto reduzindo a segregação e escoamento de água, aumenta a resistência não só ao ataque de águas sulfatadas como também à compressão do concreto e, por fim, minimiza ou retarda o progresso da reação álcali-agregado.

O primeiro passo da pesquisa de materiais pozolânicos é a determinação dos índices da atividade pozolânica - um trabalho eminentemente técnico que se executa em duas etapas: pré-qua- 
lificação pozolânica e confirmação da atividade pozolânica. A pré-qualificação pozolânica se processa mediante as análises químicas, petrográficas e as difrações de raios X. A confirmação da atividade pozolânica vai depender ainda de uma série de ensaios de preparação do material (finura por peneiramento, massa e área específicas) para, em seguida, ser efetuado o teste de pozolanicidade propriamente dito, mediante reação química com a cal ou com o cimento do material em estudo.

Esses ensaios estão estabelecidos pela Associação Brasileira de Normas Técnicas (ABNT) e se iniciam com moagem a sêco de todo material (+/- 3Kg), em moinho de bolas, durante 10 minutos. Os intervalos de moagem serão repetidos até que o resíduo retido na peneira escolhida seja menor ou igual a $20 \%$, de acordo com as condições especificadas para ensaios, prescritas na NBR 12.826/93, ou seja, para cada tipo de material (p.ex. argila) é preciso escolher a peneira (p.ex. $45 \mu \mathrm{m})$ com o respectivo fator de correção (C = 1,02), massa inicial da amostra (10g), tempo (5s) e pressão negativa de peneiramento (600mmca), para se determinar o índice de finura $(\mathrm{F}=10,66 \%$, caso o resíduo fosse igual a 1,046g), definido pela equação:

\begin{tabular}{cl}
\hline Fórmula & \multicolumn{1}{c}{ Onde } \\
\hline$F=\frac{R \cdot C}{M} 100$ & $\begin{array}{l}\mathrm{F}=\text { índice de finura; } \mathrm{R}=\text { resí- } \\
\text { duo; } \mathrm{C}=\text { fator de correção da } \\
\text { peneira; e } \mathrm{M}=\text { massa inicial (em } \\
\text { gramas) }\end{array}$ \\
\hline
\end{tabular}

Depois de enquadrado o material no intervalo especificado pelo índice de finura, ou seja, resíduo menor ou igual a $20 \%$, procede-se aos ensaios da massa e área específicas, os quais exigem do operador muita experiência e sensibilidade para a obtenção de resultados precisos e repetitivos, dentro do intervalo de erro permitido.

Para a determinação da massa específica (NBR 6474/84) são necessários frascos volumétricos calibrados contendo líquido de medição (xilol), que, para a leitura do volume inicial no banho termo-regulador, serão mantidos submersos até se obter o equilíbrio da temperatura, a qual não deve variar mais de $0,5^{\circ} \mathrm{C}$ durante o ensaio. A quantidade de amostra lançada cuidadosamente no frasco volumétrico deverá ser suficiente para fazer o líquido deslocar entre as marcas de 18 e $25 \mathrm{~cm}^{3}$. O frasco precisa ser agitado ou submetido a movimentos pendulares até que as bolhas de ar sejam eliminadas por completo. Quando o frasco volumétrico, submerso no banho termo-regulador, atingir o equilíbrio térmico, anota-se a leitura final. A massa específica, por fim, é obtida pela relação entre a massa (M) de determinada quantidade de material e o volume (V) por ela ocupado:

$$
\rho=\frac{M}{V}\left(m g / m^{3}\right)
$$

O resultado deve ser a média de, pelo menos, duas determinações que não difiram entre si mais que $0,01 \mathrm{mg} \cdot \mathrm{m}^{-3}$.

A determinação da área específica de um material em pó, mediante o uso do permeabilímetro de Blaine, é regida pela norma NBR 7224/96. O operador, novamente, precisa ter grande habilidade no manuseio do equipamento e sensibilidade não só no tratamento do material como também na inferência da porosidade.

Despeja-se a amostra numa célula de permeabilidade preparada com papel-filtro acoplada hermeticamente ao tubo manométrico. Pressiona-se firmemente o êmbolo de compactação até que o ressalto encoste na borda superior da célula. Criadas tais condições ideais do ensaio, o líquido manométrico deve ser aspirado com a mangueira e deslocado da sua posição de equilíbrio até a marca superior, ponto em que o registro deve ser fechado. Uma vez criada uma subpressão no tubo, abaixo da célula, o ar é forçado a fluir através da camada porosa e o fluido manométrico vai lentamente retornando à sua posição de equilíbrio. O tempo de escoamento do fluido deve ser registrado entre a segunda (tempo inicial) e a terceira marca (tempo final).

Por último se faz o cálculo da área específica que é dado pela equação:

\begin{tabular}{|c|c|}
\hline Fórmula & Onde \\
\hline$A_{m}=\frac{K \sqrt{\varepsilon^{3}} \sqrt{t}}{\rho(1-\varepsilon) \sqrt{\eta}}$ & $\begin{array}{l}\mathrm{A}_{\mathrm{m}}=\text { área específica em mas- } \\
\text { sa, em m }{ }^{2} \cdot \mathrm{kg}^{-1} ; \mathrm{K}=\text { constante } \\
\text { do aparelho, em } \mathrm{Pa}^{2} \times \mathrm{m}^{-1} ; \\
\varepsilon=\text { porosidade da camada; } \\
\rho=\text { massa específica do mate- } \\
\text { rial; } \mathrm{t}=\text { tempo; } \eta=\text { viscosida- } \\
\text { de dinâmica do ar (variável de } \\
\text { acordo com a temperatura). }\end{array}$ \\
\hline
\end{tabular}

Na determinação da atividade pozolânica com cal (NBR 5751/92) prepara-se uma argamassa que contenha uma parte de hidróxido de cálcio, nove partes de areia normal brasileira (NBR 7214/82), e mais uma quantidade de material pozolânico, que 
corresponda ao dobro do volume do hidróxido de cálcio. Para a moldagem de três corpos de prova cilíndricos de $50 \mathrm{~mm}$ de diâmetro por $100 \mathrm{~mm}$ de altura, deve-se utilizar as seguintes quantidades, em massa, dos materiais:

\begin{tabular}{|c|c|c|}
\hline Material & Massa (g) & Onde \\
\hline Hidróxido de cálcio & 104 & $\delta_{\mathrm{poz}}=$ massa específica do material \\
\hline Areia normal & 234 de cada uma das frações & pozolânico (NBR 6474/84). \\
\hline Material pozolânico & $2 \frac{\delta_{p o z}}{\delta_{c a l}} \times 104 g$ & $\begin{array}{l}\delta_{\text {cal }}=\text { massa específica da cal hidratada } \\
\text { (NBR 6474/84). }\end{array}$ \\
\hline
\end{tabular}

A água a ser adicionada, por sua vez, é a necessária à obtenção de uma consistência normal (NBR 7215/96). Geralmente, cumprindo-se os procedimentos exigidos por essa norma, as pozolanas consideradas de qualidade satisfatória exibem, aos 7 dias, resistência à compressão não inferior a 6,0 MPa. Este é um método considerado rápido, porque, durante 6 dias seguidos, a mistura de pozolana e hidróxido de cálcio é curada à temperatura de $55^{\circ} \mathrm{C}$ em moldes lacrados.

Na determinação da atividade pozolânica com cimento (NBR 5752/92) preparam-se duas argamassas, conforme as quantidades recomendadas, para a moldagem de três corpos de prova cilíndricos de $50 \mathrm{~mm}$ de diâmetro por $100 \mathrm{~mm}$ de altura, conforme se segue:

\begin{tabular}{|c|c|c|c|}
\hline \multirow[t]{2}{*}{ Material } & \multicolumn{2}{|c|}{ Massa (g) } & \multirow[t]{2}{*}{ Onde } \\
\hline & Argamassa A & Argamassa B & \\
\hline Cimento Portland & 312,0 & & $\begin{array}{l}\delta_{\text {poz }} \text { e } \delta_{\text {cim }} \text { são, respectivamente, massas } \\
\text { específicas do material pozolânico e do }\end{array}$ \\
\hline Material pozolânico & - & $109,2 \frac{\delta_{\text {poz }}}{\delta_{\text {cim }}}$ & cimento (NBR 6474/84). \\
\hline $\begin{array}{l}\text { Areia normal } \\
\text { Água }\end{array}$ & $\begin{array}{c}936,0 \\
X\end{array}$ & $\begin{array}{c}936,0 \\
\mathrm{Y}\end{array}$ & $\begin{array}{l}\mathrm{X} \text { e Y são as quantidades de água } \\
\text { necessárias para produzir índices de } \\
\text { consistência de } 225 \pm 5 \mathrm{~mm} \text { (NBR } 7215 / 96) \text {. }\end{array}$ \\
\hline
\end{tabular}

O índice de atividade pozolânica com cimento Portland é definido por:

\begin{tabular}{ll}
\hline \multicolumn{1}{c}{ Fórmula } & \multicolumn{1}{c}{ Onde } \\
\hline$\frac{f_{c B}}{f_{c A}} .100(\%)$ & $\begin{array}{l}\mathrm{f}_{\mathrm{cB}}=\text { resistência média, aos } 28 \\
\text { dias, dos corpos de prova mol- } \\
\text { dados com cimento e material }\end{array}$ \\
& $\begin{array}{l}\text { pozolânico (argamassa B); } \\
\mathrm{f}_{\mathrm{CA}}=\text { resistência média, aos } 28 \\
\text { dias, dos corpos de prova mol- } \\
\text { dados só com cimento (arga- } \\
\text { massa A). }\end{array}$ \\
\hline
\end{tabular}

Como se viu, esta segunda etapa, além de trabalhosa, é muito demorada: aos 28 dias de espera pelos resultados dos ensaios de confirmação da pozolanicidade somam-se outros 5 dias na preparação do material.

Em vista disso, houve a necessidade de se encontrar um método alternativo que, com maior ra- pidez e mais baixo custo, fosse capaz de indicar se uma amostra apresentava ou não potencial para reatividade pozolânica. Esta foi a motivação principal da metodologia proposta, porque, por força da limitação de tempo e de recursos financeiros, o autor principal deste artigo (MONTANHEIRO 1999) constatou, em sua pesquisa, que entre centenas de amostras, somente algumas dezenas poderiam ser encaminhadas para ensaios de confirmação de atividade pozolânica.

Assim, para aumentar o grau de confiança do potencial pozolânico do material em estudo, foi desenvolvido um ensaio rápido baseado na análise por difração de raios X de amostra coletada de uma pasta curada em estufa à temperatura constante de $30^{\circ} \mathrm{C}$, durante 7 dias. Nessa pasta constituída inicialmente por uma parte de cal e duas partes de material pozolânico, procurar-se-á identificar, pela interpretação do difratograma de raios $\mathrm{X}$, os compostos neoformados pela reação pozolânica de seus componentes, entre os quais 
está o silicato de cálcio hidratado (C-S-H). É de se ressaltar que a análise por difração de raios $\mathrm{X}$ do material natural dá um forte indicativo do potencial de reação do material, contudo, o resultado da análise da pasta curada é preciso. Este trabalho versa, então, sobre a metodologia para determinação da atividade pozolânica pela análise por difração de raios $X$.

\section{POZOLANAS}

Pozolanas são substâncias naturais ou artificiais, de composição silicosa ou silico-aluminosa que, não sendo por si sós cimentícias, reagem com hidróxido de cálcio na presença de umidade e à temperatura ambiente, resultando em compostos com propriedades cimentícias. Diversas rochas podem apresentar compósitos com propriedade pozolânica natural ou potencial a ser realçada mediante processos de ativação térmica. MIELENZ et al. (1951) classificaram tais rochas quanto à sua atividade-tipo, denominando-as "materiais pozolânicos" (Tabela 1), tomando como referência a composição química e mineralógica das próprias pozolanas.

A experiência dos autores com materiais pozolânicos do tipo 1 a 4 demonstra que estes apresentam atividade pozolânica. No entanto, é de se observar que as pozolanas obtidas de argilas calcinadas apresentam resultados muitas vezes superiores àqueles obtidos com rochas classificadas na atividade-tipo 1.

\section{REAÇÃO POZOLÂNICA}

A hidratação do cimento Portland produz hidróxido de cálcio. Tomando-se a alita $\left(\mathrm{C}_{3} \mathrm{~S}\right)$ como exemplo, a reação de hidratação se dá:

$$
\mathrm{C}_{3} \mathrm{~S} \stackrel{\mathrm{H}_{2} \mathrm{O}}{\longrightarrow} \mathrm{CSH}+\mathrm{CH}
$$

onde $\mathrm{C}=\mathrm{CaO}, \mathrm{S}=\mathrm{SiO}_{2}$ e $\mathrm{H}=\mathrm{H}_{2} \mathrm{O}$, que é a notação adotada pela indústria do cimento.

A reação pozolânica ocorre combinando-se o hidróxido de cálcio disponível com os elementos reativos do material pozolânico. Como a sílica é o principal componente ativo de um material pozolânico, pode-se ilustrar a reação pozolânica conforme segue:

$$
\mathrm{CH}+\mathrm{S} \stackrel{\mathrm{H}_{2} \mathrm{O}}{\longrightarrow} \mathrm{CSH}
$$

Observa-se que a reação pozolânica consome o hidróxido de cálcio e forma um silicato de cálcio hidratado.

Segundo MEHTA (1987), é importante verificar que a reação pozolânica consome o hidróxido de cálcio, ao passo que a reação de hidratação do cimento Portland produz hidróxido de cálcio. A figura 1 ilustra o consumo do hidróxido de cálcio durante a hidratação de um cimento Portland pozolânico, com 40\% de pozolana (LEA 1970 apud MEHTA 1987).

Na realidade, a reação pozolânica se desencadeia porque a sílica e a alumina são vulneráveis ao hidróxido de cálcio, pela fraqueza e instabilidade de suas ligações estruturais no material original, como é o caso do vidro vulcânico ou das argilas calcinadas (MALQUORI 1960).

\section{ANÁLISE POR DIFRAÇÃO DE RAIOS X}

A difração de raios $\mathrm{X}$ é uma poderosa ferramenta para estudos de pré-qualificação da atividade pozolânica de um material, pois os componentes

\begin{tabular}{|c|c|}
\hline Atividade-tipo & Materiais pozolânicos \\
\hline 1 & $\begin{array}{l}\text { Tufos e pumicitos riolíticos; tufos e pumicitos dacíticos. Alguns tufos e cinzas } \\
\text { andesíticos podem ser reativos. Tufos e cinzas basálticos e andesíticos são } \\
\text { inferiores ou totalmente insatisfatórios em qualidade. }\end{array}$ \\
\hline 2 & Terras diatomáceas e “cherts” opalinos. \\
\hline 3 & Todas as pozolanas obtidas de argilas calcinadas. \\
\hline 4 & Rochas zeolíticas (clinoptilolita, ptilolita e analcima). \\
\hline 5 & Bauxita. \\
\hline 6 & $\begin{array}{l}\text { Rochas compostas por minerais estáveis não reativos com a cal, tais como: } \\
\text { quartzo, feldspato, carbonatos, anfibólios, piroxênios, micas e a maioria dos }\end{array}$ \\
\hline & minerais formadores de rochas. \\
\hline
\end{tabular}

TABELA 1 - Classificação de materiais pozolânicos, conforme a sua atividade-tipo (MIELENZ et al. 1951). 
reativos das pozolanas destacam-se como uma banda amorfa no difratograma, no intervalo $2 \theta$, entre 18 e $32^{\circ}$. A figura 2 apresenta o resultado da análise total, via difratometria de raios $\mathrm{X}$, de uma terra diatomácea (amostra TM-169) em que as fases cristalinas são formadas, predominantemente, por quartzo e caulinita. O difratograma mostra também que a rocha estudada contém material amorfo delineado por um abaulamento da linha difratométrica, no intervalo $2 \theta$, entre 18 e $32^{\circ}$.

Este trabalho apresenta a proposta de um método de avaliação da potencialidade pozolânica via difração de raios $X$, com o objetivo de aumentar o grau de confiança das amostras pré-selecionadas para os ensaios de confirmação da atividade pozolânica.

\section{MÉTODO PROPOSTO}

O material pozolânico deve ser moído até se conseguir a finura determinada pelos padrões de granulação dos ensaios de pozolanicidade com a cal, ou seja, finura menor ou igual a 20\%, conforme prescreve a NBR 12.826/93. A amostra assim obtida deve ser seca em estufa a $110^{\circ} \mathrm{C}$, até que a massa se estabilize. Com essa amostra de pozolana preparase uma pasta composta por uma parte de hidróxido de cálcio e duas de material pozolânico. A quantidade de água a ser adicionada é, por sua vez, a necessária para obtenção de uma consistência normal (NBR 7215/96). Na realidade, a composição dessa pasta é regida por norma brasileira (NBR 5751/92) que prevê, ainda, adição de uma quantidade de areia normal (NBR 7214/82). Como esse método é baseado na interpretação do difratograma, não se fez a adição da

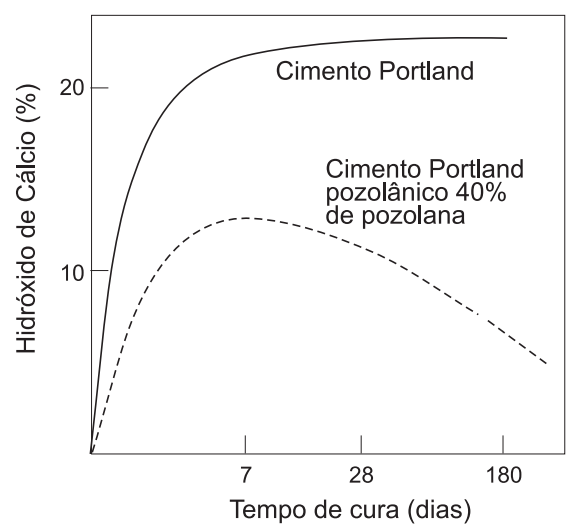

FIGURA 1 - Mudanças no conteúdo de hidróxido de cálcio durante a hidratação de um cimento Portland pozolânico (LEA 1970 apud MEHTA 1987). areia normal, porque ela poderia introduzir os picos do quartzo. A pasta assim obtida é compactada em moldes (copos plásticos de $150 \mathrm{ml}$ ) em três porções de igual volume, ao ritmo de 10 percussões/4 segundos e a 5 centímetros de altura e, em seguida, curada em estufa à temperatura constante de $30^{\circ} \mathrm{C}$ durante 7 dias. Esse tempo foi determinado em razão do consumo máximo de hidróxido de cálcio que pode ocorrer em 7 dias num cimento pozolânico (Figura 1, segundo LEA 1970, apud MEHTA 1987). A cura também poderia ser feita à temperatura ambiente, mas seria indesejável, devido às variações de temperatura diárias. Portanto, a cura foi feita em estufa à temperatura constante de $30^{\circ} \mathrm{C}$.

Após esse período, o produto obtido é moído e analisado por difração de raios X. Na interpretação do difratograma procura-se identificar os produtos neoformados da reação pozolânica, i.e., silicato de cálcio hidratado. Verifica-se, portanto, que esse método é simples, rápido, e seus resultados propiciam a avaliação do potencial da reação pozolânica do material em estudo. Aqueles que se revelarem potencialmente favoráveis à pozolanicidade deverão ser submetidos aos ensaios de confirmação da atividade pozolânica com cal/cimento em laboratórios especializados.

\section{APLICAÇÃO DA METODOLOGIA}

Com o objetivo de ilustrar o procedimento descrito, apresentamos na tabela 2 alguns exemplos da metodologia proposta escolhendo, para isso, duas amostras estudadas pelo autor principal deste trabalho (MONTANHEIRO 1999). Elas representam as atividades-tipo 1 (amostra TM-290 e TM-183) referidas por MIELENZ et al. 1951.

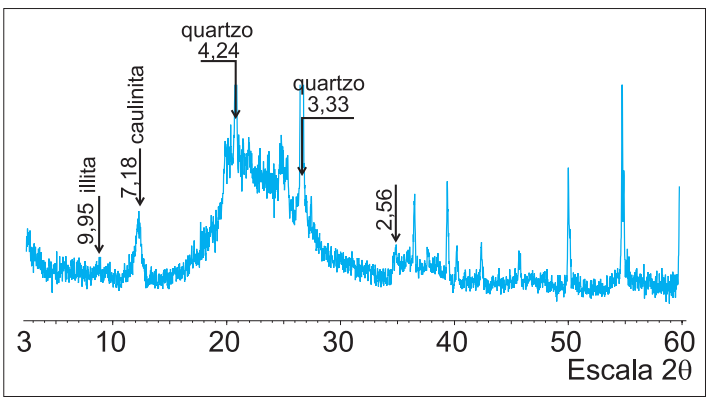

FIGURA 2 - Difratograma de raios X obtido para amostra total de terra diatomácea (amostra TM-169) mostrando os picos das fases cristalinas presentes (quartzo e caulinita) e uma banda de dispersão resultante de certa organização atômica ou molecular de material amorfo. 
A composição química das amostras (Tabela 3) indica os principais componentes químicos de interesse para a fabricação de cimento.

A figura 3 mostra fotomicrografias da amostra TM-290, onde se pode observar claramente a matriz parcialmente devitrificada apresentando ainda material amorfo (vidro vulcânico).

A figura 4 apresenta fotomicrografias da amostra TM-183. A, nícois paralelos e B, nícois cruzados. Comparativamente à amostra TM-290, esta amostra apresenta uma proporção menor de vidro vulcânico.

Em seguida, conforme a metodologia proposta, as pastas preparadas com hidróxido de cálcio (P.A.) foram curadas em estufa à temperatura constante de $30^{\circ} \mathrm{C}$ por 7 dias, e submetidas às análises de difração de raios $\mathrm{X}$ e microscopia eletrônica de varredura.

A figura 5 mostra dois pares de difratogramas de raios X das amostras de dacito (amostras TM-290 e TM183) e o difratograma do hidróxido de cálcio P.A.. Cada par é formado, respectivamente, pelo difratograma da amostra natural e pelo difratograma da pasta curada.

No difratograma da pasta curada é possível observar a emergência de dois picos característicos de compósitos mineralóides gerados durante a reação pozolânica. O primeiro pico de 3,05 angstrons é característico de um silicato de cálcio hidratado $\left(\mathrm{Ca}_{2} \mathrm{SiO}_{4} \cdot \mathrm{H}_{2} \mathrm{O}\right)$, e o segundo - de 7,51 angstrons - do mineral girolita $\left(\mathrm{Ca}_{8} \mathrm{Si}_{12} \mathrm{O}_{30}(\mathrm{OH})_{4} \cdot 7 \mathrm{H}_{2} \mathrm{O}\right)$. Por outro lado, comparando os difratogramas "pasta curada versus hidróxido de cálcio”, verifica-se que ainda persistem os picos correspondentes à portlandita (hidróxido de cálcio), indicador de que o consumo do reagente na reação pozolânica não foi total.

A análise por microscopia eletrônica de varredura permite confirmar os compósitos mineralóides na reação pozolânica, conforme ilustrado pela figura 6. Nesta vista geral da pasta curada de dacito + hidróxido de cálcio (amostra TM-290), destaca-se uma textura rendilhada, típica de um silicato de cálcio hidratado (C-S-H) e, ainda, compósitos

TABELA 2 - Amostras selecionadas para exemplificar a metodologia proposta.

\begin{tabular}{|c|c|c|}
\hline Amostra & Descrição & Localização \\
\hline TM-290 & $\begin{array}{l}\text { Rocha constituída por quartzo, plagioclásio, cristobalita, } \\
\text { mordenita e hematita. Na matriz vítrea (65\% do total da } \\
\text { rocha), parcialmente devitrificada, distribuem-se } \\
\text { pseudomorfos de piroxênio, fenocristais de plagioclásio e } \\
\text { cristalitos, minerais opacos e amígdalas (calcedônea ou } \\
\text { zeólitas). Classificação da rocha: dacito. }\end{array}$ & $\begin{array}{l}\text { Coordenadas UTM: } \\
\text { 664,70E; 7431,60N- } \\
\text { Piraju/SP }\end{array}$ \\
\hline TM-183 & $\begin{array}{l}\text { A rocha estudada em lâmina possui uma composição } \\
\text { mineral formada pelos seguintes componentes } \\
\text { principais: vidro vulcânico ( } 75 \%) \text {; plagioclásio/piroxênio } \\
\text { (15\%) e zeólitas/quartzo ( } 10 \%) \text {. Na matriz vítrea, } \\
\text { totalmente devitrificada, distribuem-se microcristais } \\
\text { opacos (parcialmente limonitizados) e fenocristais de } \\
\text { plagioclásio do tipo labradorita. Pseudomorfos de } \\
\text { piroxênio totalmente substituídos por filossilicatos } \\
\text { castanhos e magnetita com bordas intemperizadas } \\
\text { constituem componentes traços. Zeólitas e quartzo são } \\
\text { os principais minerais das amígdalas. Classificação da } \\
\text { rocha: dacito. }\end{array}$ & $\begin{array}{l}\text { Coordenadas UTM: } \\
\text { 641,30E; 7442,60N } \\
\text { Fazenda Santa Virgínia, } \\
\text { Ipaussu/SP }\end{array}$ \\
\hline
\end{tabular}

TABELA 3 - Componentes químicos das amostras estudadas. Teor dos principais óxidos em \% em peso, determinados pelo método ICP; PPC = perda ao fogo em \%.

\begin{tabular}{ccccccccc}
\hline Amostra & $\mathrm{PPC}$ & $\mathrm{SiO}_{2}$ & $\mathrm{Al}_{2} \mathrm{O}_{3}$ & $\mathrm{Fe}_{2} \mathrm{O}_{3}$ & $\mathrm{CaO}$ & $\mathrm{MgO}$ & $\mathrm{Na}_{2} \mathrm{O}$ & $\mathrm{K}_{2} \mathrm{O}$ \\
\hline TM-290 & 1,40 & 67,13 & 12,61 & 7,18 & 1,85 & 0,33 & 3,46 & 3,79 \\
TM-183 & 2,40 & 66,17 & 12,98 & 7,04 & 1,91 & 0,54 & 2,76 & 3,75 \\
\hline
\end{tabular}


mineralóides de formato placóide (Figura 7). Alguns pontos do campo visual mostrados nesta figura foram analisados com raios $\mathrm{X}$ por energia dispersiva (EDS) e revelaram que os compósitos mineralóides neoformados - incluindo-se aqueles de formato placóide - são compostos químicos de silicatos hidratados de cálcio, alumínio, potássio, sódio e magnésio (Figura 8). Desse modo, entende-se que o vidro vulcânico presente no dacito (amostra TM290) possui alumínio, potássio, sódio e magnésio em sua composição química, os quais são incorporados na formação do silicato de cálcio hidratado durante a reação pozolânica.

Após esses estudos, as amostras naturais de dacito foram submetidas aos ensaios de confirmação de atividade pozolânica com cal. Conforme os resultados obtidos (Tabela 4) pode-se concluir que somente a amostra TM-290 apresenta resistência à compressão acima de 6,0 MPa (conforme norma NBR 12653/92), que a caracteriza como pozolana natural. A amostra TM-183 apresenta um índice inferior, dado por porcentual menor de vidro vulcânico que o verificado para a amostra TM-290. Entretanto, a metodologia apresentada deu um forte indicativo de que é possível identificar a reação pozolânica em rochas naturais utilizan- do-se a análise por difração de raios X para os produtos da reação pozolânica, devido ao aparecimento de picos correspondente a cristais de reyerita, girolita, gismondita e, principalmente, C-S-H(Figura 5).

\section{CONCLUSÃO}

Este trabalho apresentou um método rápido para avaliação da propriedade pozolânica de rochas mediante a análise por difração de raios X, técnica que é normalmente utilizada na pré-qualificacão da atividade pozolânica de materiais. No entanto, se usada em pastas curadas com hidróxido de cálcio, pode revelar os produtos neoformados na reação pozolânica e, com isso, confirmar ou indicar o potencial de reatividade pozolânica de uma rocha. A metodologia proposta traz algumas vantagens em relação aos procedimentos usuais: reduz o tempo gasto para se obter um resultado negativo, reduz custos com análises e otimiza a seleção das amostras a serem analisadas. Se os ensaios de preparação e confirmação da atividade pozolânica apresentam um custo da ordem de US\$270,00 por amostra com resultados que demoram 40 dias em média, o potencial de reatividade pozolânica pode ser conhecido em 10 dias a custos da ordem de
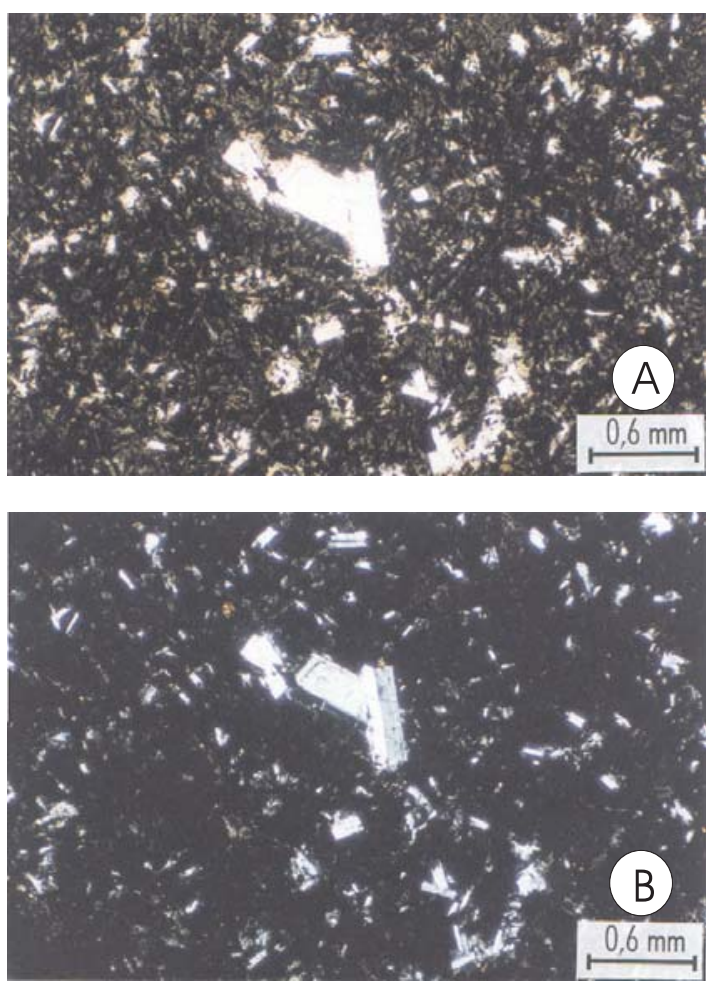

FIGURA 3 - Fotomicrografias de dacito (amostra TM290). (A) nícois paralelos e (B) nícois cruzados.
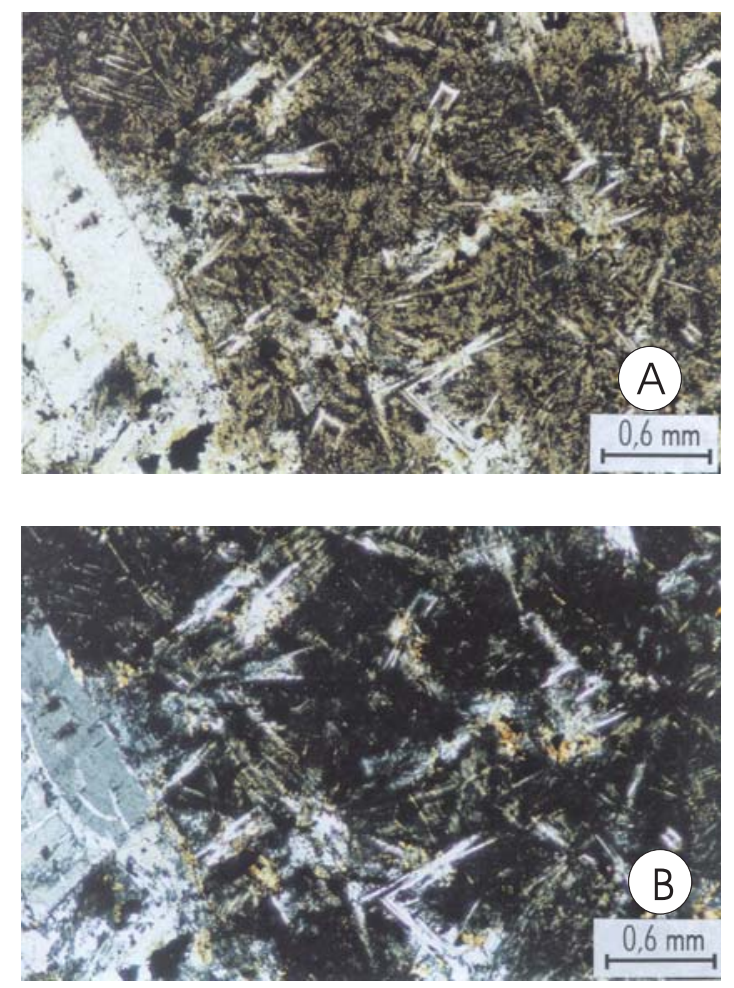

FIGURA 4 - Fotomicrografias de dacito (amostra TM183). (A) nícois paralelos e (B) nícois cruzados. 


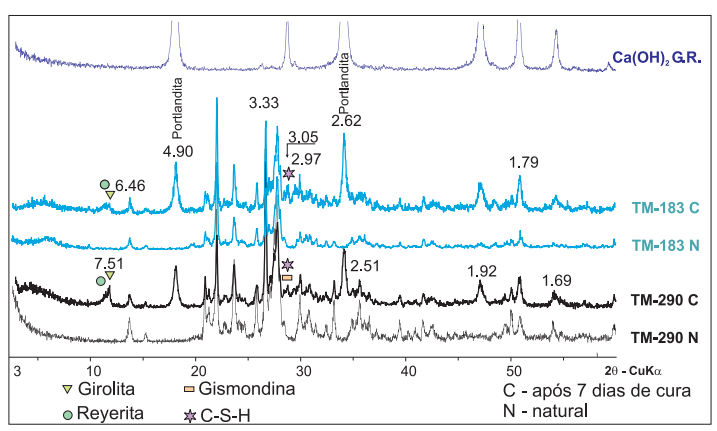

FIGURA 5 - Difratogramas de raios $\mathrm{X}$ obtidos para amostras totais de dacitos naturais (amostra TM-290 e TM-183) e pasta de hidróxido de cálcio + dacitos após 7 dias (curada); e para hidróxido de cálcio (P.A.).

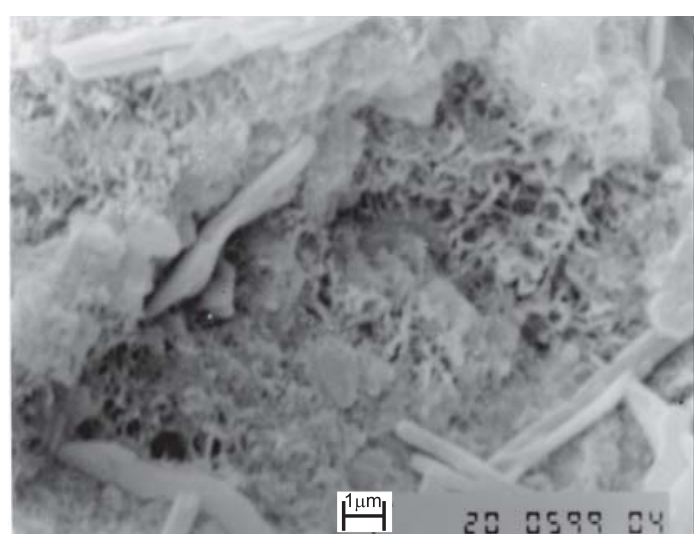

FIGURA 6 - Formas rentilhadas típicas de silicato de cálcio hidratado (C-S-H) formadas após reação pozolânica da pasta de hidróxido de cácio + amostra TM-290. Imagem ao microscópio eletrônico de varredura.

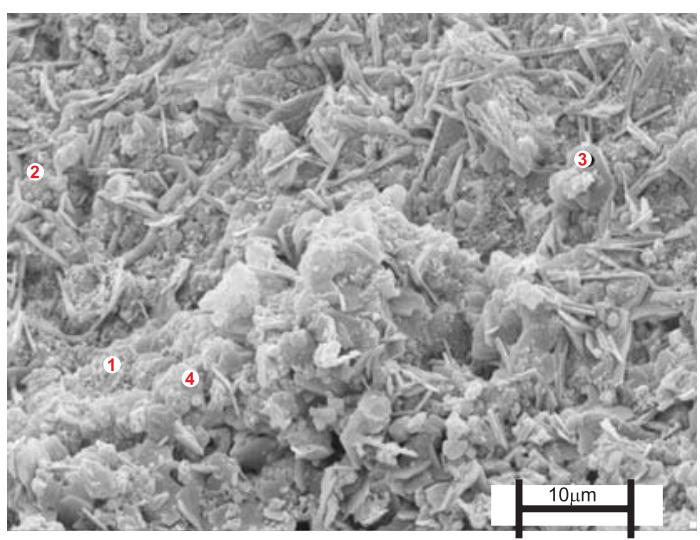

FIGURA 7 - Compostos formados na reação hidróxido de cálcio e dacito. Imagem do microscópio eletrônico de varredura.
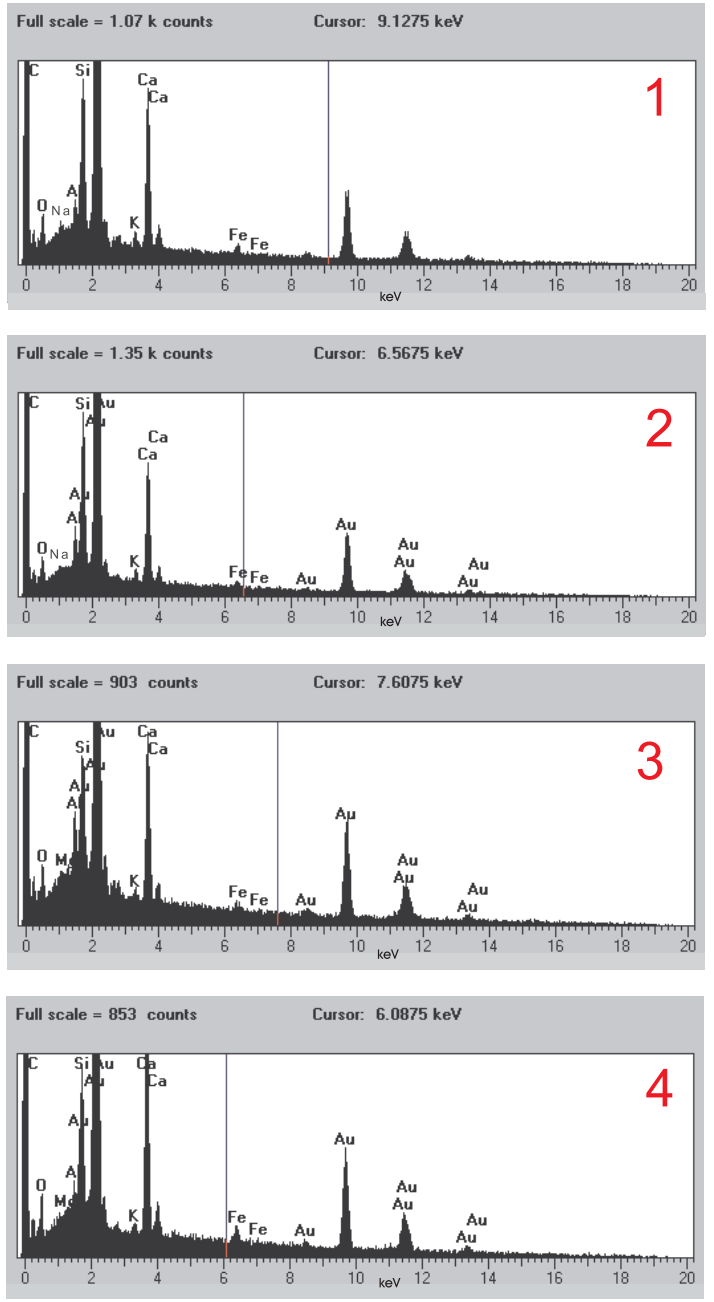

FIGURA 8 - Espectros de EDS obtidos para os quatro pontos mostrados na figura 7.

US $\$ 27,00$ por amostra. Essa rapidez com os resultados das análises também tem importância estratégica tanto na condução dos trabalhos prospectivos como na seleção de áreas potencialmente promissoras para a pesquisa de pozolanas. Trata-se de um método expedito e simples, pois o material a ser ensaiado não precisa passar pela caracterização de todos os índices físicos, que pode demorar vários dias. É óbvio que, selecionadas as amostras, os ensaios de qualificação da atividade pozolânica em materiais geológicos devem ser feitos segundo a metodologia consagrada e adotada pela indústria do cimento.

\section{AGRADECIMENTOS}

Os autores expressam os seus sinceros agradecimentos à Fundação de Amparo à Pesquisa do Estado de São Paulo - FAPESP (Processo 95/8815-3) 
Revista do Instituto Geológico, São Paulo, 24(1/2), 1-9, 2003.

TABELA 4 - Resultados de ensaios para determinação do índice de atividade pozolânica com cal, conforme norma NBR 5751/92.

\begin{tabular}{cccccc}
\hline Amostra & $\begin{array}{c}\text { Massa } \\
\text { específica } \\
\left(\mathrm{g} \cdot \mathrm{cm}^{-3}\right)\end{array}$ & $\begin{array}{c}\text { Área } \\
\text { específica } \\
\left(\mathrm{cm}^{2} \cdot \mathrm{g}^{-1}\right)\end{array}$ & $\begin{array}{c}\text { Resíduo } \\
\text { peneira } \\
45 \mu \mathrm{m}(\%)\end{array}$ & $\begin{array}{c}\text { Quantidade } \\
\text { de água (g) }\end{array}$ & $\begin{array}{c}\text { Índice de } \\
\text { atividade } \\
\text { pozolânica (MPa) }\end{array}$ \\
\hline TM-183 & 2,58 & 8610 & 7,3 & 232 & 4,3 \\
TM-290 & 2,66 & 8400 & 9,8 & 230 & 6,4 \\
\hline
\end{tabular}

pela outorga de auxílio que permitiu a realização desta pesquisa, ao Professor Jayme Antonio Montanheiro pela correção do texto e aos relatores, cujas contribuições melhoraram o manuscrito.

\section{REFERÊNCIAS BIBLIOGRÁFICAS}

ASSOCIAÇÃO BRASILEIRA DE NORMAS TÉCNICAS (ABNT) 1982. NBR7214/82. Areia normal para ensaio de cimento: especificação.

ASSOCIAÇÃO BRASILEIRA DE NORMAS TÉCNICAS (ABNT) 1984. NBR6474/84. Determinação da massa específica.

ASSOCIAÇÃO BRASILEIRA DE NORMAS TÉCNICAS (ABNT) 1992a. NBR5751/92. Materiais pozolânicos - Determinação de atividade pozolânica com cimento Portland - Índice de atividade pozolânica com cal.

ASSOCIAÇÃO BRASILEIRA DE NORMAS TÉCNICAS (ABNT) 1992b. NBR5752/92. Materiais pozolânicos - Determinação de atividade pozolânica com cimento Portland - Índice de atividade pozolânica com cimento.

ASSOCIAÇÃO BRASILEIRA DE NORMAS TÉCNICAS (ABNT) 1993. NBR12826/93. Determinação do índice de finura por meio de peneirador aerodinâmico.
ASSOCIAÇÃO BRASILEIRA DE NORMAS TÉCNICAS (ABNT) 1996. NBR7215/96. Cimento Portland - Determinação da resistência à compressão. Anexo B - Informativo do Índice de consistência normal.

ASSOCIAÇÃO BRASILEIRA DE NORMAS TÉCNICAS (ABNT) 1996. NBR7224/96. Determinação da área específica.

LEA, F.M. 1970. The chemistry of cement and concrete. $3^{\text {rd }}$. Ed., New York, Dover Publishing, v. 1, 375p.

MALQUORI, G. 1960. Portland-Pozzolan Cement. In: INTERNATIONAL SYMPOSIUM ONTHE CHEMISTRY OF CEMENT, 4, Washington, D.C., Paper VIII-3,2:983-1006.

MEHTA, K. 1987. “Natural Pozzolans”. Supplementary Cementing Materials for Concrete, CANMET-SP86-8e, Canadian Government Pubblishing Center, Supply and Services, Ottawwa. V1, p.1-33.

MIELENZ, R.C.; GREENE, K.T.; SCHIELTZ, N.C. 1951. Natural pozzolans for concrete. Economic Geology, 46:311-328.

MONTANHEIRO, T.J. 1999. Prospecção e caracterização de pozolanas na Bacia do Paraná, Estado de São Paulo. Instituto de Geociências, Universidade de São Paulo, São Paulo, Tese de Doutoramento, 226p.

Endereço dos autores:

Tarcísio José Montanheiro - Instituto Geológico, Secretaria do Meio Ambiente do Estado de São Paulo. Avenida Miguel Stéfano, 3900 - CEP 04301-903 - Água Funda, São Paulo/SP. E-mail: tjmonta@igeologico.sp.gov.br

Jorge Kazuo Yamamoto/Yushiro Kihara: Instituto de Geociências, Universidade de São Paulo. Rua do Lago, 562 - CEP 05508-900 - Cidade Universitária, São Paulo/SP. 